\title{
Music Therapy In Early Intervention - A Family Perspective
}

\author{
Susana Gutiérrez Jiménez \\ PhD, Music Therapist, \\ Cerebral Palsy Association, Évora, Portugal. \\ Vítor Franco \\ PhD, Psychologist, Department of Psychology, \\ University of Évora, Portugal
}

\begin{abstract}
Music Therapy (MT) in Early Intervention currently works with children with disabilities or at risk of developmental delays in a family-centered model. Within a family centered approach the way parents receive and understand all the intervention is crucial, but has not been properly considered. This paper aims to identify the role and value of MT in the perspective and representations of parents that attended therapy sessions with their children in the context of an Early Intervention Program. Grounded Theory methodology is used to analyze data collected through interviews with 7 mothers and fathers of children with severe disabilities. Results show the significant value families set on Music Therapy specific interventions to facilitate motor areas, social and interpersonal relationships and engagement with music and sounds. Three large categories show that families are able to understand MT in Early Intervention context: what is Music Therapy, what are its benefits, and the effects it has on early development. Music Therapy can be applied in the practice of Early Intervention teams and is compatible with a family-centered programs. It has the capacity to provide an effective contribution to improve nonverbal communication in primary relationships, particularly in more severe disorders when communication is unconventional. This work also allows to broaden current concepts on the clinical practice of MT in Early Intervention, moving from a traditional clinical approach to a family-centered one.
\end{abstract}

Key words: Music Therapy, Early Intervention, Disability, Developmental Disorders, Familycentered practice

\section{INTRODUCTION}

Music Therapy is the use of music and sounds to promote integral human development in the psychological, physiological and social aspects. Music is thought to extend on a nonverbal plane that helps human beings express their intimate feelings and emotions in all physical, intellectual and social areas.

Del Olmo (2005) states music works as a semiotic mediator between infants and adults and can allow understanding what happens when basic emotional feelings such as anger, joy, fear, dislike or surprise, are expressed. The author emphasizes music effects are linked to the hearer's states of motivation, emotion and perception. According to Ruud (1993) Music Therapy also has an impact on implementation, promotion, prevention and rehabilitation of the physical, mental, emotional and social health of people, groups and communities, including its intervention with babies and their mothers. From the neurosciences perspective, Koelsch (2009) stresses the importance of early treatment for prevention, which is coincident with the Early Intervention perspective. 
Despite the few studies published about perceptions or opinions of families attending Music Therapy sessions with their children, Jonsdottir (2008) finds that parents recognize that their children, even with severe developmental disorders, respond to different sonorous and musical stimuli with gestures and movements. Families are thus encouraged to explore their children's spontaneous responses.

Nevertheless Music Therapy must deal with a larger conception of early Intervention that is not just a rehabilitative and treatment perspective.

\section{Early Intervention system in Portugal}

Early Intervention programs are much more than an early answer to the needs of a child with a disability or whose healthy development is at risk. It is actually a complex system of coordinated services based on a family-centered approach that assigns the family a key role in the quality care of child development.

All children born with an unfinished maturation process and newborns brain plasticity makes them more fragile to face adverse environmental conditions, but also favors their development. Early Intervention takes into account that the central nervous system is more flexible during maturation, so children under 6 years benefit from accessing early intervention in this stage, and will have better chances to maximize their potentials. Thus, environmental factors and social responses have a significant impact on child development.

Early Intervention Network is based on theoretical principles of development, including the contributions of neurosciences, the interactional and transational perspectives (Sameroff and Mackenzie, 2003) and the engagement of caregivers, and above all, the bio-ecological model and systemic perspective that stresses the importance of the contextual factors affecting child development (Bronfenbrenner and Morris, 2006). Three basic principles are implicit in different definitions: the principle of globality, the principle of contextuality and the principle of opportunity. The principle of globality emphasizes the understanding of the child as a whole, and so, all the different developmental domains must be addressed simultaneously to meet each child's individual needs and provide support accordingly. The contextual principle assumes that the child behaves and develops in the context of a family, society and culture. The principle of opportunity recognizes that the intervention must be adequately and personally timed to meet the real needs of the child and family.

The modern perspectives of Early Intervention are family-centered, thus, all children with developmental disorders, or exposed to the risk, should receive bio-psychosocial assistance with a prevention and welfare approach in order to potentiate their development and wellbeing, which will result in a more complete personal autonomy and inclusion into family, school and social environments.

Early Intervention network in Portugal is managed to satisfy the needs of families and children and the programs delivered by team-based transdisciplinary service model. This network (the SNIPI- National System of Early Intervention on Childhood) is ruled by a legal framework, simultaneously sponsored by the ministries of Education, Health and Social Welfare. The latest update of the Portuguese law defines Early Intervention as: "an integrated set of child and family centered care policies and procedures to promote prevention and rehabilitation in the areas of education, health care and social welfare" (Decreto-lei 281/2009, 2009).

With this objective, the SNIPI is run on a community base all over the country. Local direct intervention teams work on a family-centered approach based child daily life routines, 
supported by community resources, local authorities, associations and facilities (Franco, Melo, Santos, Apolónio \& Amaral, 2017).

The local intervention teams integrate teachers, psychologists, speech therapists, physiotherapists, occupational therapists, social workers and other professionals, eventually a music therapist. All intervention is seen from a global family-centered perspective and these professionals work within a transdisciplinary approach.

\section{Music Therapy in Early Intervention}

In Early Intervention the Music Therapist holds sessions with the child and family to collaborate and promote the different stages of development with sonorous, musical and ludic activities, as follows (Lazo 1998): a) Sonorous and visual stimulation activities; b) Rhythmic and expressive movement activities; c) Music and movement activities; d) Vocal projection and breathing exercises.

Music Therapy highlights the importance of the sonorous-musical background of the family and of the socio-cultural environment since psychological and neurological aspects interact in emotional responses. Benenzon, de Gainza and Wagner (1998) enphazise the specific aspects of each individual's background and also that the emotional response to a sonorous and musical stimulus lies on each subject's cultural variables and life history. Soria-Urios, Duque and Garcia-Moreno (2011) describe five factors that make Music Therapy effective in Early Intervention: a) Attentional modulation : uses the attraction of music to call attention in a more powerful way than other sensual stimuli; b) Emotional modulation: uses music to modulate emotions and elicit emotional responses involving cortical and subcortical regions of the brain; c) Cognitive modulation: brain networks process music and memory involves the processes of encoding, storing and retrieval; d) Behavioural modulation or: music can evoke movement patterns even unconsciously (rhythmic auditory stimulation is also used for rehabilitation in brain injury and motor disorders); e) Communicative modulation or interpersonal factor: music is communication and can be used to improve nonverbal communication skills.

Koelsch (2009) also describes three domains for the beneficial therapeutic effects of Music Therapy. The first is the emotions domain, with clear-cut effects on limbic structures as well as on the autonomic nervous, endocrine and immune systems. Second, the perceptual and motor development domain as musical perception activates the auditory and motor brain areas favoring motor skill learning and improving comprehension abilities. And third, the social cognitive domain, because music activates brain networks: anterior medial prefrontal cortex, superior temporal sulcus and temporal lobes.

Practice of Music Therapy in the context of Early Intervention aims to develop psychomotor and perceptual-cognitive areas and has a positive impact on parent-child and socio emotional communication.

However, in moving from a therapeutic model to a family-centered model, it is essential to verify the extent to which the goals and practices of Music Therapy are congruent. For this, it is important that the family has a clear perception of what MT is and how it works.

\section{OBJECTIVES OF THE STUDY}

This study aims to know parental perception on the use of Music Therapy in Early Intervention family-centered programs, focusing on how it can to meet the needs of children and family. 
The specific objectives are: a) Find out what Music Therapy means to parents; b) Know what benefits parents see in Music Therapy; c) Find out the outcomes they feel had an impact in their children's lives.

\section{METHODS}

Considering the objectives of the present study, the option was for a qualitative approach, listening parents and paying close attention to their perception and opinions, as "qualitative methods can be used to explore substantive areas about which little or about which much is known to gain novel understandings" (Strauss and Corbin 2002,12).

We opted for the constructionist approach of Grounded Theory because no theory was guiding us in this process of parents listening.

Grounded Theory approach generates a latent theory directly from data. Its methodology is analytical, with an insight on data collection and by means of systematically applied methods it uses an inductive approach to generate a substantive code. The study findings constitute a theoretical formulation or an integrated set of conceptual hypotheses about the substantive area under the study (Glaser, 1992, 14).

This methodology allows direct knowledge about the individuals involved by paying attention to their views and experiences. The intention is not to test a theory but to interpret the phenomenon under study.

Six mothers, aged 29-42 years, and a 43 years old father, were interviewed. All of them have severely disabled children, and receive services delivered by an Early Intervention Service Team (Local Early Intervention Service Team Nr. 2, Cerebral Palsy Association, Évora, Portugal).

(Table 1. Participants)

\begin{tabular}{|c|c|c|c|c|}
\hline \multicolumn{5}{|c|}{ Table 1. Participants } \\
\hline Case/Code & $\begin{array}{l}\text { Date of } \\
\text { birth }\end{array}$ & Diagnosis & $\begin{array}{l}\text { Age of El } \\
\text { starting }\end{array}$ & $\begin{array}{c}\text { Age at Music } \\
\text { Therapy } \\
\text { starting }\end{array}$ \\
\hline $\begin{array}{l}\text { Case } 10 \\
\text { cod RP } 01\end{array}$ & $\begin{array}{l}\text { December } \\
1999\end{array}$ & Angelman Syndrome & $4 ; 5$ & $5 ; 2$ \\
\hline $\begin{array}{l}\text { Case 2 }{ }^{\pi} \\
\text { cod RP } 02\end{array}$ & $\begin{array}{l}\text { May } \\
2008 \\
\end{array}$ & $\begin{array}{l}\text { Global Neuromotor Developmental Delay. } \\
\text { Metabolic Disease }\end{array}$ & $1 ; 8$ & $1 ; 9$ \\
\hline $\begin{array}{l}\text { Case } 3 \text { o } \\
\text { cod RP03 }\end{array}$ & $\begin{array}{l}\text { January } \\
2000\end{array}$ & $\begin{array}{l}\text { Congenital Hydrocephalus } \\
\text { with Spastic Triplegy. Severe Visual Disabi- } \\
\text { lity. }\end{array}$ & $0 ; 6$ & $5 ; 9$ \\
\hline $\begin{array}{l}\text { Case } 4 \text { ऽ } \\
\text { Cod RP04 }\end{array}$ & $\begin{array}{l}\text { August } \\
2007\end{array}$ & Autism Spectrum Disorder & $0 ; 4$ & $2 ; 7$ \\
\hline $\begin{array}{l}\text { Case } 5 \text { P } \\
\text { Cod RP05 }\end{array}$ & $\begin{array}{l}\text { September } \\
2003\end{array}$ & $\begin{array}{l}\text { Hydrocephalus causing Cerebral Palsy, } \\
\text { Severe Motor Developmental Delay, Spastic } \\
\text { Tetraparesis, Blindness. }\end{array}$ & $4 ; 2$ & $4 ; 11$ \\
\hline $\begin{array}{l}\text { Caso } 6 \text { P } \\
\text { Cod RP06 }\end{array}$ & $\begin{array}{l}\text { Juliy } \\
2006\end{array}$ & Autism Spectrum disorder & $3 ; 3$ & $3 ; 11$ \\
\hline $\begin{array}{l}\text { Case } 7 \hat{\jmath} \\
\text { Cod RP07 }\end{array}$ & $\begin{array}{l}\text { July } \\
2004\end{array}$ & $\begin{array}{l}\text { Hydrocephalus, Cerebral Palsy, Spastic Te- } \\
\text { traparesis, Severe Cognitive Delay. }\end{array}$ & $1 ; 0$ & $2 ; 2$ \\
\hline
\end{tabular}


The interview started with three questions: 1 . What is Music Therapy to you?; 2 . Why did your child do Music Therapy, and how useful was it?; 3. How do you think your child benefited from Music Therapy sessions?

Interviews last twenty minutes long, on average, were audio-recorded and complete transcriptions were used for analysis.

Data collected from interviews were coded, compared and conceptualized. We started with line-by-line open coding of data based on GT, categorizing them to fit the questions of the study. In this way, new categories emerged, which were grouped and given code names along with memo writing, in different colors, for categorization.

Memos were then conceptually aligned to guide us to the next step. Codes were sorted into categories, subcategories and dimensions to fit the questions from the data. Indicators and properties were analyzed to form an analytical framework. In this stage it was necessary to explore relationships between categories and a complex mapping connection between them was identified.

This sorting process, followed by conceptualization and description, revealed parents' overall perception about Music Therapy in Early Intervention contrasting different incidents to a theoretically saturate core and related concepts.

\section{RESULTS}

Results were grouped in three categories: 1) What is Music Therapy?; 2) How useful is it? 3) What were the results?

\section{What is Music Therapy?}

From the line-by-line analysis we found out how parents describe Music Therapy. Three main subcategories were identified: Therapy, Well-being and Development. 
(Figure 1. What is Music Therapy)

Figure 1. What is Music Therapy?

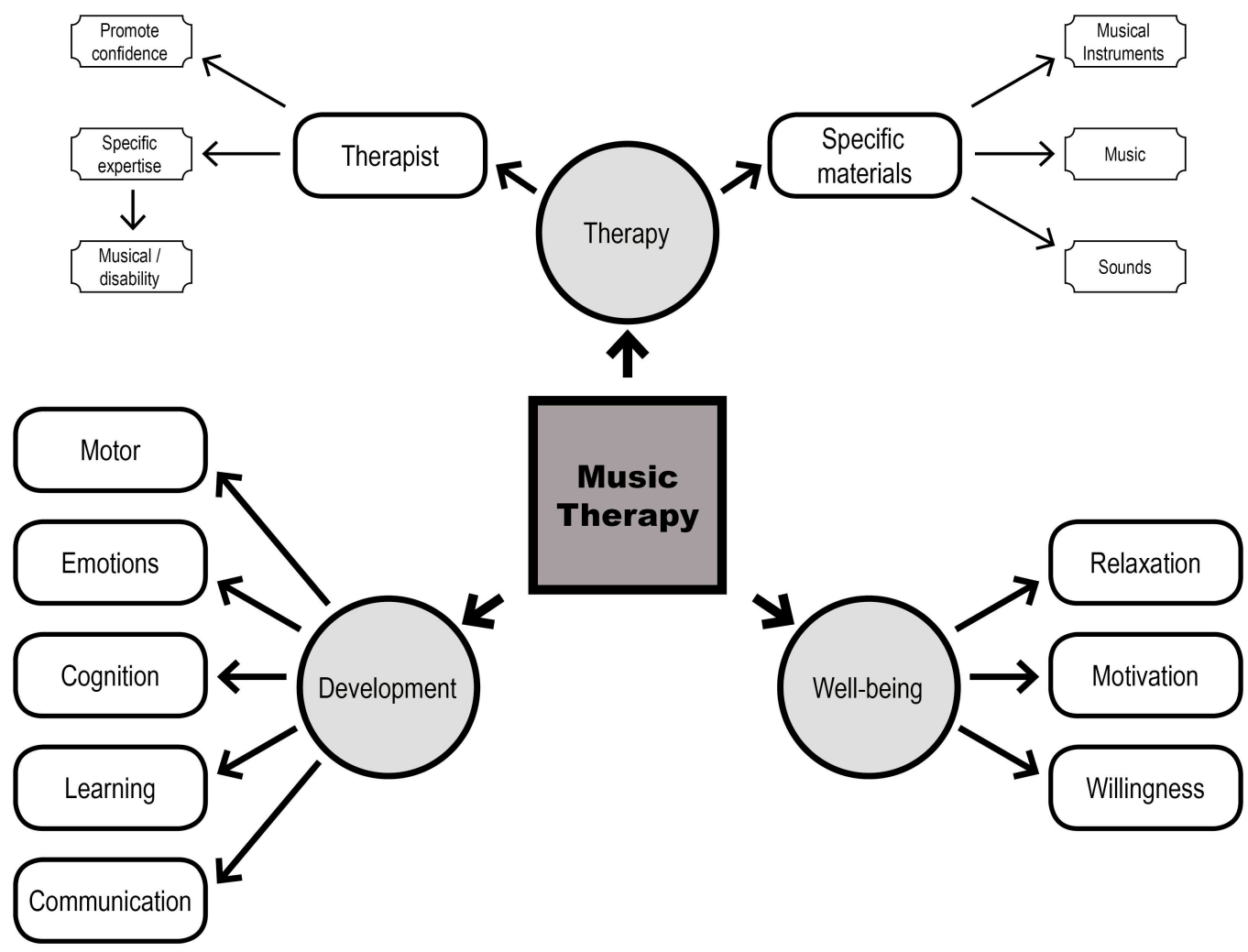

a) Therapy - Parents describe Music Therapy as a therapy through music. They specify two dimensions: the therapist and the use of specific materials or means.

The Music Therapist is someone with specific expertise in music and in disability issues. Parents first define Music Therapy as a treatment through the creation of music, but later they identify their experiences in Music Therapy sessions with the Early Intervention team and conclude they managed to develop a reliable and trusting relationship with the Music Therapist.

"It is important for us because we later trust the work they do" (EP04)

The therapist's professional training and knowledge of their children's pathologies are also see as fundamental because they feel confident this intervention will give their children treatment for their specific disorders.

Specific Materials consists of parents' views of the specific materials used by the Music Therapist: musical instruments, sounds and music. They recognize Music Therapy mainly uses music and colorful musical instruments with timbric and sound intensity that elicit their children's responses.

"Playing with musical objects, he likes everything related to music... I think all this has to do with Music Therapy" (EP01)

b) The second subcategory is Well-being: we grouped parents' descriptions reflecting the impact of this therapy because it is pleasurable and builds their children's state of well-being. They also think that materials or music itself engage them into the activities and this therapy 
definitely fosters well-being. This subcategory is presented through three dimensions: Relaxation, Motivation and Willingness.

Dimension Relaxation is referred as a very important feature of Music Therapy because the children feel physically and mentally relaxed.

"...for me, Music Therapy is...I think it is relaxing for children like mine ... It's good" (EP07)

In this example, the parent explains how Music Therapy gives her child, with spastic cerebral palsy, a sense of peace.

Dimension Motivation considers data in which parents describe Music Therapy as one of the therapies their children enjoy and how they are always happy to attend sessions.

"She has always liked music, she has never paid attention to television but she has to music a lot, yes, it soothes her a lot... When we started coming here, I noticed she liked everything to do with sounds, she stopped to listen to everything and... She takes an interest in everything and then therapist suggested my daughter should take up Music Therapy and I think she is doing well... whenever she hears anything, she generally doesn't look but she starts listening" (EP05).

Dimension Willingness is identified because parents think music not only produces well-being but also elicits in their children positive responses to attending Music Therapy sessions. They feel Music Therapy is also pleasurable and enjoyable and start describing in detail the emotions their children feel in the sessions.

"He loves Music Therapy. He is very happy when he comes to the sessions" (EP02)

c) Subcategory Development includes parents' descriptions of Music Therapy as a practice that responds to children's different stages of global development and their perceptions that sounds have the potential to stimulate them.

"In my opinion, Music Therapy is stimulation through sounds" (EP05)

This subcategory identifies five levels:

- Motor: according to parents' considerations, playing instruments is associated with the body and e motor activity;

- Emotions: it refers to child development and mood variability.

- Cognition: the interviewees find Music Therapy aims to develop cognitive capacity, such as responding when called by the name or to simple orders.

- Communication: in this dimension we grouped all data identifying communication since children with severe pathologies mainly communicate through sonorous expressions. Thus, parents find Music Therapy to be a direct intervention in their children's production.

- Learning: The interviewees feel that Music Therapy can help improve children's learning and development. 


\section{Benefits of Music Therapy in Early Intervention}

Parents also identified two subcategories of benefits of Music Therapy for children: a) Pleasurable Activity and b) Therapeutic Objectives, which are intertwined according to parents' opinions about the ludic and therapeutic character of music.

a) Subcategory Pleasurable Activity is referred to MT as an enjoyable activity because it engages the children. It was necessary to include the dimension Ludic Activities because parents view Music Therapy intervention as beneficial because it enables them to play with their children during the sessions. They understand that Music Therapy is through play. And a dimension Musical Activities within parents refers that children express pleasure when listening and accompanying music.

(Figure 2. Benefits of Music Therapy in Early Intervention) Figure 2. Benefits of Music Therapy in Early Intervention

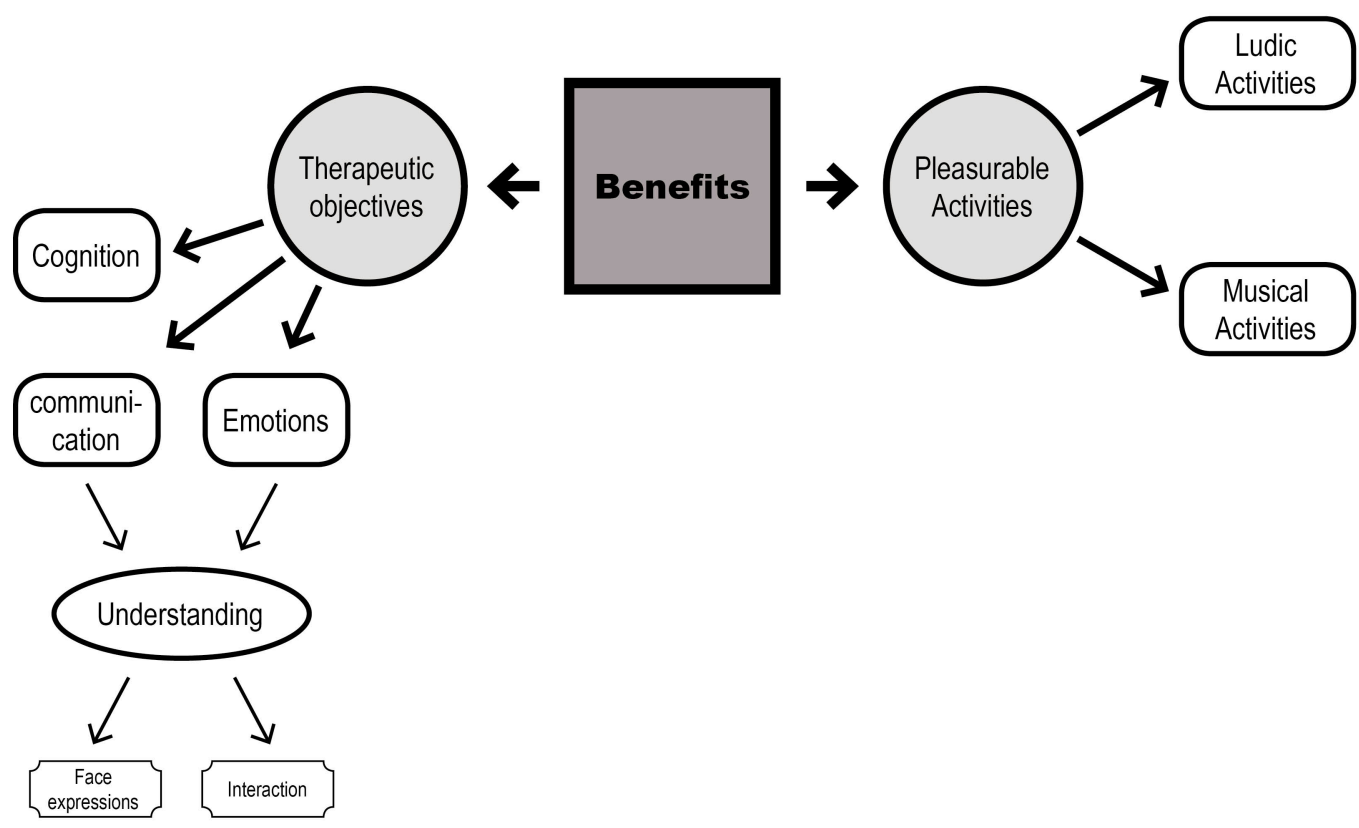

b) Benefits are mainly referred to the Therapeutic Objectives of Music Therapy through the framing and causality functions of music. Parents consider Music Therapy fosters development and also reduces parental stress or depression. They describe this subcategory in three dimensions:

- Level of Emotion: Data reveal Music Therapy fosters the emotional expression, influencing the different stages of their children's development.

- Level of Communication: parents state that, above all, Music Therapy promotes their children's communicative intention and their own ability to understand them.

"She has improved her hearing, she tries to imitate the sounds she hears with her hands and many sounds with her hands and mouth. And it's the only way we can understand what she wants and it is through those sounds that we are getting to understand her. Her progress is due to Music Therapy" (EP03). 
By improving gestural expression, Music Therapy facilitates the child's own interaction with his nuclear family with the reassurance it can also function in their everyday lives.

Parents describe music as a pleasurable and healthy activity that gives their children immediate satisfaction through ludic activities and helps them communicate by gestures and in turn, facilitates parent-child interaction.

- Cognitive level: Parents recognize that Music Therapy sessions improve children's cognitive skills, as shown in this example:

"He has started to help us, well, if we ask him for an object he looks for it, if we sometimes ask him to do something or bring us something, he sometimes manages to do so" (RP01).

According to parents, their children's auditory attentional capacity increased during treatment.

"The benefits of Music Therapy I have always noticed are...., she stops to listen and pay attention to anything. If people talk to her ...... she pays more attention and well..., that was what I noticed more" (RP05).

From this category, we infer that parents perceive Music Therapy aims to improve interpersonal relationships since it enables them to better understand what their children express.

\section{Effects of Music Therapy in Early Intervention}

It emerges from our data parents' views of the long and short-term effects of this intervention process.

a) Short term effects: this subcategory grouped the descriptions of the immediate effects of a Music Therapy session during the therapeutic process. It was set in 3 dimensions;

- Motivation: grouping of data from parents stating that one of the immediate effects of Music Therapy is motivate to action.

- Intention: grouping of data stating Music Therapy sessions result in an improvement of children's intentionality.

- Communication: it was found in both subcategories of the main category Effects. Parents find in this dimension that communication is one of the most tangible outcomes observed in their children and they think it is the result of Music Therapy sessions. They believe that Music Therapy has therapeutic goals that are transferred into other areas of children's daily life and rotines.

"And even at home we have noticed her progress, the best she has achieved is her hearing. And we notice it at home daily...." (RP03). 
(Figure 3. Effects of Music Therapy in Early Intervention)

Figure 3. Effects of Music Therapy in Early Intervention

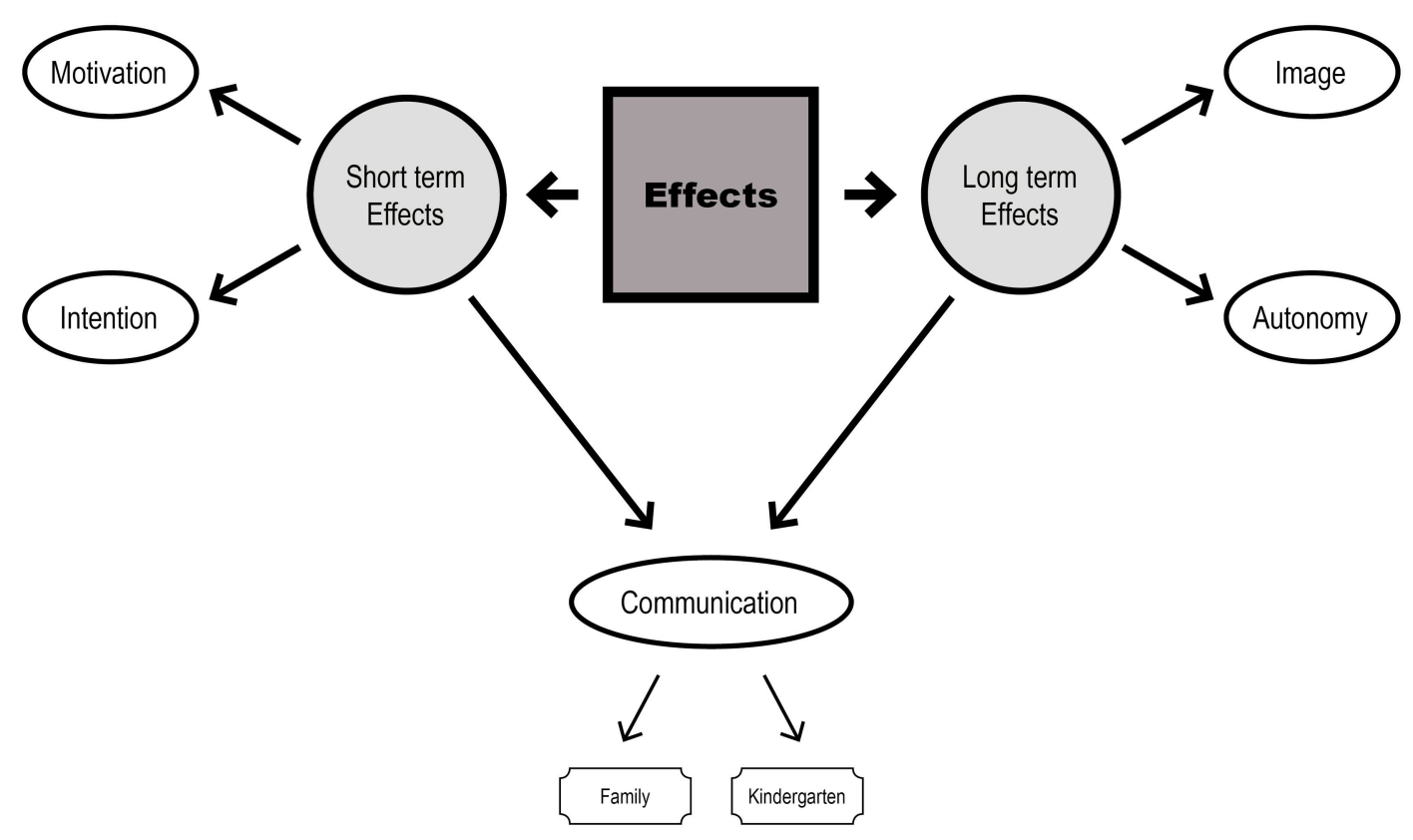

Parents also refer that all the voice projection activities and breathing exercises in Music Therapy sessions contribute to improve their children's self-expression.

"It's very noticeable. The therapist kept insisting on his moving arms and trying to touch and now we can see he tries and wants to grab... he also makes sounds to create laughter, he used to laugh inwardly but now he laughs openly. And if there is a difference in the sounds he makes now this is the result of Music Therapy" (RP02).

b) Long term effects: We took together all the results or effects parents consider persistent over time and that were acquired with the support of Early Intervention teams. They realize these effects are beneficial for their children's future and that can still be observed today. This subcategory was presented through three dimensions:

- Image: this dimension include all descriptions stating Music Therapy helps a change of image when a medical perspective of disability is replaced by a social model of disability becomes explicit in kindergarten or in the extended family. Thus, parents started building a more positive image of their children.

"I like it for him because I can see he feels more self-confident" (EP04)

- Autonomy: parents describe how their children manage to engage in some activities with an increasing degree of autonomy as a result of the support provided by the Early Intervention Team.

"It's been good for him... Before he didn't use to have his milk from a straw and now he does. He didn't use to take cookies to his mouth and now he does, and all this is the result of the work done" (EP01). 
- Communication: we took together the data from parents referring to service coordination between Kindergarten and Family. This dimension is also found to be significant in shortterm effects. In fact, parents report Music Therapy facilitates children's verbal communication with their nuclear or extended families and even with their peers and teachers in the educational context of kindergarten.

\section{DISCUSSION AND CONCLUSIONS}

Parents' perceptions and perspectives on Music Therapy have been scarcely studied despite the interest the practice of this intervention generates, especially when it is family-centered, as it is the case of Early Intervention services nowadays (Franco et al, 2017).

From the first paper of Trehub and Trainor (1998) on musical discrimination at early ages, only few studies have been published on the concept of Music Therapy considering the perception of parents of disabled children. Chiang (2008) finds that parents/caregivers notice a high degree of motivation in children with disabilities that attend Music Therapy sessions, and that this motivation moves on to other spaces where the child interacts. Furthermore, parents admit that they also benefit from attending these sessions with their children because they feel music is stress-reducing.

According to Kern and Aldridge (2006) and Benenzon (1998) parents remark Music Therapy sessions improve their children's psychomotor skills and social, psychological and intellectual functioning in their daily life.

Our data show that parents recognize Music Therapy is comforting for their children. This description is very important because it is from parents whose seriously handicapped children underwent, in early stages of life, partially invasive clinical practices that caused the children's physical discomfort and parents' emotional distress. These parents also compare MT to other therapies their children went into and highlight its ludic and pleasurable approach. In their opinion, Music Therapy facilitates their children's cognitive and motor development motivating them from a ludic approach through music or the use of musical instruments. Trolldalen (2009) questions the appreciation and recognition in musical interaction and describes four different areas where potentially significant changes can be observed as from the process of Music Therapy. These areas are also considered conclusive in the present study: a) emotional sharing; b) play and social interaction; c) balance to focus attention; d) social skills.

When we ask parents about their opinions about benefits of Music Therapy, we find they feel dependent to their children's cognitive, perceptual and motor disabilities but they find Music Therapy facilitates their playful interaction with their children. They refer their children can listen to music, recognize and identify sounds or tunes or even play an instrument in Music Therapy sessions and this activity means doing something. According to Haslbeck (2013), MT empowers parents to potentiate their children's creativity and autonomy in terms of emotional responsiveness, thus creating a healthy parent-child interaction.

It is worth mentioning that all these children have deficit in symbolic play, show little interest in objects like dolls and feel more attracted to multi-sensory light-up toys. They do not express graphically or have spontaneous social interaction with peers and are dependent on parents' care. However, parents reported that by means of musical activities they find their children can do different things and that sounds also promote parent-child interaction. 
If so, Musical Therapists play an essential role considering their professional training and the affectionate involvement with the child and family. Parents greatly value a Music Therapist with openness to new ideas and clear set objectives. Music Therapy is considered a therapy facilitated by a well-trained Music Therapist and parents appreciate the importance of this music-based intervention in their children's development. They feel primarily satisfied with this therapy because it promotes parent participation and provides them with a space that facilitates interaction with their children, therefore potentiating child global development.

Since these parents also play the role of caregivers, which is time, energy and care consuming, they sense Music Therapy offers them a relaxing atmosphere to play with their children, play musical instruments and elicit their responses as well. Thompson (2014) also advocates that sonorous-musical activities help build the bond between parents and children with severe communication difficulties and also improve communication skills.

Parents understand it is of central importance the way the Music Therapist offers a full explanation of each of the activities and of the goals intended to achieve in the sessions since this is a key factor in ensuring a trust relationship between the family and the Early Intervention team.

Parents also recognize the use of music in music-therapeutic processes is an effective tool for helping their children relax and feel better with their own bodies. It also aims to improve the child physical capacities, like breathing and emotional expressions like laughter. Parents feel these are specific Music Therapy competencies.

In conclusion, parents regard that Music Therapy, along with other therapies, is a significant intervention to support the needs of their handicapped children. One of the main and most effective benefits of Music Therapy is about communication. These children present a nonverbal condition and Music Therapy facilitates their speech development and activates their own pre-language acquisition to help them interact better with parents, educational contextes or extended family.

The category Communication involves the concept of understanding lallation or sounds their children make and Music Therapy helped parents interpret them.

As for benefits or outcomes, parents also find that the activities in Music Therapy sessions are transferred or have effects on their children's daily life. In this way, parents acquire pragmatic knowledge of therapy and intervention and value the outcomes resulting of their active participation and close relationship with the children. They find their children reflect improvements in facial expressions, relaxation and breathing capacity as immediate effects and recognize some kind of autonomy as a long-term effect, which they associate with the activities in Music Therapy sessions.

We can conclude that Music Therapy can be used with good success in the context of Early Intervention, because it has the capacity to provide an effective approach to improve nonverbal communication in primary relationships particularly in more severe disorders when communication is unconventional. Music Therapy can be applied in the practice of Early Intervention teams and is compatible with family-centered programs.

\section{References}

Benenzon R.O., de Gainza, V. H. \& Wagner, G. (1998). La Nueva Musicoterapia. Buenos Aires: Numen. 
Bronfenbrenner, U., \& Morris, P. A. (2006). "The bioecological model of human development," in Handbook of Child Psychology: Theoretical Models of Human Development, 6th Edn, Vol. 1, eds W. Damon and R. M. Lerner (Hoboken, NJ: Wiley), 793-828. doi: 10.1002/9780470147658.chpsy0114

Chiang, J. Y. K. (2008). Music therapy for young children who have special needs: the music therapy experience from the perspectives of carers and professionals. Thesis of Master of Music Therapy at the New Zealand School of Music, Wellington, New Zealand.

Decreto-lei 281/2009. (6 de Outubro de 2009). Diario da República (2009). 1a Série-N’193- 6 de Outubro de 2009, pp. 7298-7302. Lisboa, Portugal.

del Olmo Barros, M. J. (2005). Musicoterapia en Atención Temprana. Música, terapia y comunicación. Revista de Musicoterapia, (25), 9-18.

Franco, V. (2015). Introdução à Intervenção Precoce no desenvolvimento da criança; com a familia, na comunidade, em equipa. Évora: Aloendro.

Franco, V., Melo, M., Santos, G., Apolónio, A., \& Amaral, L (2017) A National Early Intervention System as a strategy to promote inclusion and academic achievement in Portugal. Frontiers in Psychology, 8: 1137 (doi:

10.3389/fpsyg.2017.01137)

Glaser, B.G. (1992). Basics of grounded theory analysis. Mill Valley, CA: Sociology Press.

Haslbeck, F. B. (2014). The interactive potential of creative music therapy with premature infants and their parents: A qualitative analysis. Nordic Journal of Music Therapy, 23(1). 36-70.

Jonsdottir V. (2008). Music therapy and early intervention from a caring perspective. In Trondalen G., Ruud E. (Eds.), Perspektiver på Musikk og helse. 30 år med norsk musikkterapi [Perspectives on music and health. 30 years with Norwegian music therapy] (pp. 364-384). Oslo, Norway: Norges musikkhøgskole

Kern, P., \& Aldridge, D. (2006). Using embedded music therapy interventions to support outdoor play of young children with autism in an inclusive community-based child care program. Journal of Music Therapy, 43(4), 270294.

Koelsh, S. (2009) ). A Neurocientific perspective on music therapy. Annals of the New York Academy of Sciences, 374-384.

Lazo, P. (1998). Musicoterapia: Una propuesta educativa-terapeutica. Universidad del Salvador, 127-136.

Ruud, E. (1993). Los Caminos de la Musicoterapia: la Musicoterapia y su relación con las teorías terapéuticas actuales. Buenos Aires: Bonum.

Sameroff, A. J., and Mackenzie, M. J. (2003). A quarter century of the transitional model of child development: How things have changed? Zero Three 24, 14-22.

Soria-Urios, G., Duque P. \& Garcia-Moreno J.M. (2011). Música y cerebro (II): evidencias cerebrales del entrenamiento musical. Revista Neurologia, 53(12).739-46.

Strauss, A. \& Corbin, J. (2002). Bases de la investigación cualitativa: técnicas y procedimientos para desarrollar la teoría fundamentada. Medelin: Universidad Antioquia.

Thompson, G. (2014). A Survey of Parents' Use of Music in the Home With Their Child with Autism Spectrum Disorder: Implications for Building the Capacity of Families. Voices: A World Forum For Music Therapy, 14(1). (doi:10.15845/voices.v14i1.734).

Trehub, S. E. \& Trainor, L. (1998). Singing to Infants: Lullabies and Play. In Rovee-Collier, C., Lipsitt, L. P. \& Hayne H. (Eds.) Advances in Infancy Research, 12, 43-77.

Trodlladen, G. (2009). A Music Therapy Project with Mothers and Children Elucidated through the Concept of «Appreciative Recognition». Nordic Journal of Music therapy 6 (1). 14-27. 